\title{
Transforming Problem-Based Learning through Abductive Reasoning
}

\author{
Noeman Mirza \\ Thompson Rivers University, noeman.mirza@gmail.com \\ Noori Akhtar-Danesh \\ McMaster University, daneshn@mcmaster.ca \\ Charlotte Noesgaard \\ McMaster University, noesgaar@mcmaster.ca \\ Lynn Martin \\ McMaster University, mart|@mcmaster.ca \\ Carolyn Byrne \\ McMaster University, cbyrne@mcmaster.ca
}

Follow this and additional works at: https://qane-afı.casn.ca/journal

\section{Recommended Citation}

Mirza, Noeman; Akhtar-Danesh, Noori; Noesgaard, Charlotte; Martin, Lynn; and Byrne, Carolyn (2017) "Transforming Problem-Based Learning through Abductive Reasoning," Quality Advancement in Nursing Education - Avancées en formation infirmière: Vol. 3: Iss. 2, Article 2.

DOI: https://doi.org/10.17483/2368-6669.1121

This Article is brought to you for free and open access by Quality Advancement in Nursing Education - Avancées en formation infirmière. It has been accepted for inclusion in Quality Advancement in Nursing Education - Avancées en formation infirmière by an authorized editor of Quality Advancement in Nursing Education - Avancées en formation infirmière. 


\section{Introduction}

The small-group problem-based learning (PBL) pedagogy was introduced at McMaster University in the 1960s to shift focus from the traditional teacher-centred approach to education (Rideout, 2001). As a new method of teaching, PBL introduced a student-centred pedagogy where learning was stimulated by hypothetical scenarios and problems, which learners sought out to resolve through self-directed learning and tutor guidance (Barrows \& Tamblyn, 1980; Rideout \& Carpio, 2001). According to Barrows and Tamblyn, the thinking process of PBL is founded upon hypothetico-deductive reasoning, which emerged from Elstein, Shulman, and Sprafka's (1978) work on medical problem-solving. Not only is hypothetico-deductive reasoning the principal form of reasoning in PBL within nursing education (Rideout, 2001), but it is also the main method of reasoning in non-PBL nursing curricula (Wong \& Chung, 2002).

Based on the work of Barrows and Tamblyn (1980) and Elstein et al. (1978), when a clinician uses hypothetico-deductive reasoning to explain care situations, she relies on initial cues from the situation to stimulate the recognition and retrieval of a few pre-existing explanations from her memory that could potentially explain the situation. These plausible explanations or "hypotheses" are then tested through further data collection, which allows the clinician to either accept or refute her initial hypotheses in light of the collected data. If the hypotheses cannot sufficiently explain the presenting situation, the clinician retrieves more hypotheses from her memory and tests them until one or a few hypotheses are confirmed based on their ability to explain the situation.

Although the context of small-group learning within PBL may cater to learning needs of nursing students, novice nursing students cannot be expected to recognize cues and retrieve existing hypotheses from their memories in order to explain a nursing-focused care situation, which they are encountering for the first time. Students may be able to identify that the client in the situation is upset or is having difficulty coping with his illness, but they may face difficulty explaining underlying nursing concepts, which novice students have neither encountered in the past nor learned in a clinical practice context. Therefore, issues with hypothetico-deductive reasoning and its use within PBL must be considered and challenged in order to maximize learning for novice nursing students within a small-group learning context.

Haig (1999), Ward and Haig (1997), and Lawson and Daniel (2011) contend that a clinician using hypothetico-deductive reasoning generates hypotheses based on initial and limited cues that may be different from the underlying cause of the care situation. Ward and Haig claim that from initial hypotheses, the clinician moves to hypothesis testing without emphasis on hypothesis creation or hypothesis building through the acquisition of broad-range data from the care situation. Furthermore, it is argued that hypothetico-deductive reasoning is rooted in positivism (or empiricism), which favours empirical knowing with little or no emphasis on other ways of knowing (Monti \& Tingen, 1999). For such reasons, hypothetico-deductive reasoning is viewed as using a narrow scope for explaining care situations (Haig, 1999; Rolfe, 1997).

Another form of reasoning, abductive reasoning, looks beyond the mere retrieval of hypotheses from one's existing memory and perceives hypothesis generation as the creation of hypotheses through the synthesis of broader data collection (Eriksson \& Lindström, 1997; Peirce, 1998; Raholm, 2010a). This definition is similar to the definition of hypothesis generation

presented by Fisher, Gettys, Manning, Mehle, and Baca (1983), which focuses on the creation rather than the retrieval of hypotheses. 
In this paper, we introduce abductive reasoning as a new approach to exploring care situations within nursing education. We argue that abductive reasoning, if utilized by educators to educate students, may shed new light on the discovery and development of strong knowledge structures among nursing students, especially those who are at the novice stage. This paper first explains the philosophical underpinnings of abductive reasoning. It then compares the process of hypothesis generation between abductive and hypothetico-deductive reasoning. This is followed by an example care scenario to demonstrate how learners can apply the principles of abductive reasoning. Finally, the paper discusses possible implications of abductive reasoning on nursing education.

\section{Background}

In the history of inquiry, the first task of empirical research was to sort true from false. This was performed by deriving new truths from existing truths based on observations or facts that were logically self-evident (Shank, 1998). After this, a need for a systematic way to draw further truths surfaced, which gave rise to deductive inference (Tarski, 1941). Aristotle's syllogism became a basic tool for deductive reasoning as it allowed researchers to apply one true claim to another and derive a conclusion (e.g., if $\mathrm{A}=\mathrm{B}$ and $\mathrm{B}=\mathrm{C}$, then $\mathrm{A}=\mathrm{C}$ ) (Longley, 1981).

For centuries, empirical reasoning in the western world relied on deduction until inductive inference originated during the scientific revolution between the 13th and 14th centuries (Deely, 1992). However, it was not linked to scientific inquiry until the 16th and 17th centuries through the work of Fancis Bacon (Shank, 1998). While deductive inference allowed specific truths to be derived from general truths, inductive inference allowed generalizations to be derived from specific truths (Raholm, 2010a, 2010b). Induction eventually replaced deduction and became the appropriate way of resolving empirical issues (Shank, 1998).

Induction was criticized by several philosophers in the 19th and 20th centuries. Popper (2013) argued that it is impossible to prove scientific theories as true through induction since no amount of evidence guarantees the absence of contrary evidence. He suggested that science can only be accomplished through the testing of hypotheses. His work, along with his predecessors, gave rise to the hypothetico-deductive inference, which is also known as the scientific method (Haig, 2014). Hypothetico-deductive reasoning was adopted as the main method of reasoning by health disciplines that aimed to produce health professionals who could think like scientists (Elstein et al., 1978; Patel, Arocha, \& Zhang, 2005; Tanner, Padrick, Westfall, \& Putzier, 1987).

In the 19th and 20th centuries, philosopher C. S. Peirce introduced abductive inference as a form of synthetic reasoning through which meaningful underlying patterns of selected phenomena are recognized in order to generate hypotheses that explain a complex reality (Eriksson \& Lindström, 1997; Raholm, 2010a, 2010b). Abductive reasoning was introduced in clinical psychology as a logical method of discovering hypotheses (Haig, 1999, 2008; Vertue \& Haig, 2008; Ward \& Haig, 1997). However, in nursing, this reasoning approach remains philosophical and requires practical exploration (Lipscomb, 2012; Mirza, Akhtar-Danesh, Noesgaard, Martin, \& Staples, 2014; Raholm, 2010a).

According to Peirce (1998), abductive reasoning is the first stage of inquiry. While hypothetico-deductive reasoning is founded upon empiricism (i.e., scientific method), abductive reasoning is founded upon pragmatism, a school of thought which views that one cannot achieve truth but can only get close to it-i.e., the best explanation is not entirely true but is an account closest to the truth (Fann, 1970; Raholm, 2010a). This idea of creating the best account of truth is 
also known as inference to the best explanation (Thagard, 1978). This is different from hypothetico-deductive reasoning, which focuses on hypothesis testing.

In basic science education, abductive reasoning training is known to enhance brain activation patterns among students, which has been observed to improve students' problemsolving and hypothesis generation abilities (Kwon, Lee, Shin, \& Jeong, 2009). It has also been documented that the development of hypothesis generation abilities enhances students' logical and creative thinking and scientific reasoning abilities (Lawson, 1995). Research evidence indicates that it is not prior knowledge; rather, it is abductive reasoning skills involved in making prepositions which create the potential for excelling in hypothesis generation (Kwon, Jeong, \& Park, 2006).

Nursing literature on abductive reasoning is limited and views abductive reasoning from a philosophical lens only (Eriksson \& Lindström, 1997; Lipscomb, 2012; Mirza et al., 2014; Raholm, 2010a, 2010b; Reed, 1995; Rolfe, 1997). In the field of nursing knowledge development, both inductive and deductive reasoning are emphasized and discussed (Chinn \& Kramer, 2014), but abductive reasoning is not recognized. Even in psychology literature about hypothesis generation, abductive reasoning and its practicality on the practice of health care professionals remains theoretical (Vertue \& Haig, 2008).

\section{Hypothesis Generation}

Based on the work of Sumanthi and Saravanavel (2008), it can be concluded that there are two types of hypotheses: descriptive and relational. Descriptive hypotheses are concerned with the existence of one variable (e.g., pain), while relational hypotheses relate two variables together (e.g., pain related to hernia). While descriptive hypotheses simply define an issue, relational hypotheses are further divided into correlational and explanatory hypotheses. Correlational hypotheses indicate that two variables occur together in some manner, but one may affect the other (e.g., pain decreases as the surgical incision heals). Explanatory (causal) hypotheses, however, imply that the presence of or a change in one variable causes an effect on the other variable (e.g., pain is caused by infection at the site of the surgical incision).

While descriptive and relational hypotheses are two different forms of hypotheses, in PBL literature in nursing, the term "hypothesis" usually refers to descriptive rather than relational hypotheses. This is apparent when hypothesis generation is often referred to as the generation of issues, which denotes descriptive hypotheses rather than relational hypotheses (Ingram, Ray, Landeen, \& Keane, 1998; Rideout \& Carpio, 2001). This is due to the lack of clarification between these two terms in nursing literature. Therefore, based on Barrows and Tamblyn (1980), Fisher et al. (1983), Rideout and Carpio (2001), and Sumathi and Saravanavel (2008), we describe issue generation as the formulation of a list of problems based on the perception and interpretation of information presented in a situation (i.e., descriptive hypotheses, single variables) and hypothesis generation as the automatic and creative process of using knowledge and experience to formulate provisional propositions which explain and relate specific issues (i.e., relational hypotheses, two or more variables).

\section{Hypothesis Generation in Hypothetico-Deductive Reasoning}

The thinking process in PBL is based on hypothetico-deductive reasoning (Barrows \& Tamblyn, 1980). Building on the work of Barrows and Tamblyn, and Rideout and Carpio (2001), the reasoning process within a PBL tutorial can be described as follows: 
1. Nursing students acquire initial cues from the presented care situation and retrieve a few previously-known hypotheses which they believe could potentially explain the care situation. This gives rise to learning gaps (i.e., whether or not a previouslyknown hypothesis fits the present care situation).

2. Students engage in a self-directed, information-gathering journey and apply the newly acquired information to the care situation. This enables them to either confirm or refute their initial hypotheses.

3. If any hypotheses are confirmed, they are accepted as the explanation for the presenting care situation. However, if hypotheses are refuted, then more hypotheses are retrieved in the hopes that they may better explain the care situation.

Hypothetico-deductive reasoning has drawn criticism in its approach to hypothesis generation. Scholars argue that previously-known hypotheses often cause health care professionals to search for specific additional data to support or prove their initial hypotheses (Norman, Brooks, Colle, \& Hatala, 1999; Simmons, Lanuza, Fonteyn, Hicks, \& Holm, 2003). Not only could this lead the health care professional to neglect other data which may also be important. This could happen if the health care professional is not familiar with the other data or lacks an understanding of the relevance of that data in a particular care situation.

Other scholars such as Ward and Haig (1997) argue that the initial phase of hypotheticodeductive reasoning involves the generation of early hypotheses from limited cues. This gives the false impression that the reasoning process begins with hypothesis generation rather than a complete detection of underlying patterns or relationships within the data. According to Buckingham and Adams (2000), initial hypotheses based on incomplete data may be incorrect and could lead to the generation of inaccurate final hypotheses or diagnoses.

\section{Hypothesis Generation in Abductive Reasoning}

While hypotheses guide further learning within PBL, it is important for nursing students to generate hypotheses that explain a broad range of issues in a care situation (Ingram et al., 1998). However, a method of reasoning that focuses on hypothesis testing rather than hypothesis creation could reduce opportunities for facilitators to promote the discovery of hypotheses. For this reason, critics of hypothetico-deductive reasoning draw attention towards abductive reasoning, which they believe to be a broader method for understanding and explaining issues and their relationships in care situations (Haig, 1999; Ward \& Haig, 1997).

Vertue and Haig (2008) theorize the process of abductive reasoning within the context of clinical reasoning. Their proposed approach to clinical reasoning is theoretical and has only been described in nursing literature through a concept analysis of abductive reasoning by Mirza et al. (2014). The abductive reasoning approach proposed by Vertue and Haig (2008) consists of five steps:

1. Phenomena detection is initiated when the clinician collects and analyzes data from the presenting situation.

2. The clinician infers causal mechanisms to identify potential causes and suggest their possible relationship to the detected phenomena.

3. The clinician develops a causal model in which various causal mechanisms are interlinked. 
4. The clinician evaluates the causal model by ensuring all relationships are coherent and supported by data.

5. The clinician formulates the case through a comprehensive and integrated conceptualization that explains the various links within the causal model.

While these five steps are different from hypothetico-deductive reasoning, they lead to the same outcome-i.e., an explanatory hypothesis that explains the presenting care situation. Since abductive reasoning is believed to offer a more synthetic approach to explaining care situations as compared to hypothetico-deductive reasoning (Ward \& Haig, 1997), its introduction as a new approach within nursing education warrants exploration. It could suggest new directions for research and curriculum development aimed at enhancing classroom learning and clinical practice, especially in the context of promoting higher-order thinking among students. The next section describes a step-by-step method of how abductive reasoning can be incorporated in problem- and inquiry-based learning where care scenarios are used to initiate learning within nursing and other health sciences education.

Application of Abductive Reasoning in Problem and Inquiry-Based Learning. By considering PBL recommendations by Rideout and Carpio (2001) and Barrows and Tamblyn (1980), abductive reasoning recommendations by Vertue and Haig (2008), and other theoretical ideas discussed previously (e.g., Mirza et al., 2014), a detailed abductive approach to PBL is proposed and applied to a care situation. The aim of this proposed approach is to guide both the training of facilitators and students in creating hypotheses which aim to explain the presenting situations within PBL and beyond.

\section{Sample Care Scenario: Kelly (Age 14)}

My mother caught me vomiting a few times so she insisted that I visit the nurse. It's nothing really. They were just random episodes. My mother gets overly worried. She says I don't take care of my body and that I need to eat more. I'm growing, but I don't want to be fat. Only if I didn't get so hungry all the time, I'd be slim like Heather. My boyfriend is always talking about her. My mother doesn't care about my life. She only cares about my poor grades. Sometimes, I can't sleep because I want to eat. So I just drink water. My mother calls me a zombie, which hurts my feelings. I mean ... all the girls I know do the same to stay fit. I'm not the only one with these episodes you know.

\section{Phase 1: Phenomena Detection.}

Description. Nursing students perceive and interpret data in order to detect phenomena presented in a care situation.

To complete this phase, nursing students must

1. collect a broad range of data from the care situation;

2. interpret the collected data in order to identify issues (phenomena); and

3. formulate a comprehensive list of phenomena which represent the collected data.

Application of Phase 1. The student reads the situation and collects and interprets a variety of data in light of his previous knowledge and understanding. For example, data such as "I don't want to get fat" may be interpreted as fear of weight gain and "she only cares about my 
poor grades" may be interpreted as poor academic performance. Once a comprehensive list of phenomena is detected, the student is ready to move to the second phase of abductive reasoning.

\section{Phase 2: Development of Causal Model.}

Description. Nursing students infer causal mechanisms for phenomena and analyze their relationships with one another through an illustration.

To complete this phase, nursing students must

1. use existing knowledge and a justifiable theoretical approach (e.g., biopsychosocial framework) to organize thinking;

2. apply existing empirical, experiential, and axiological knowledge to infer possible causal mechanisms of phenomena and illustrate existing and potential relationships between causal mechanisms and/or phenomena; and

3. evaluate the causal model by ensuring relevant existing and potential relationships are not omitted and all proposed relationships are reasonably coherent.

Application of Phase 2. The causal model is developed through an illustration. To do this, the student selects a framework (e.g., biopsychosocial framework-i.e., biological, psychological, social). He writes these categories on the different corners of a page and indicates the detected phenomena under each category by using nodes (cells that contain the phenomena or concept). For example, under the social category, the student draws three nodes in which he will write the three different phenomena (i.e., poor school performance, peer pressure, and poor child-parent bonding). He does the same for the other two categories. Under biological, the student may categorize vomiting, malnutrition, hunger, and sleep deprivation, and may categorize denial, body image, low self-esteem, and jealousy under the psychological category.

The student then identifies possible causal mechanisms of each detected phenomenon by either linking it to the other phenomena that exist in the model or by generating new concepts within the causal model to act as causal mechanisms for a specific phenomenon. For example, within the biological category, the student might identify that an eating disorder or poor eating habits (new concepts) may be possible causes of the malnutrition and being underweight that Kelly (the person in the scenario) is experiencing. Similarly, the student continues to generate various causal mechanisms for other remaining phenomena in the biological, social, and psychological categories. He then links these concepts by drawing arrows to connect them with one another and to the original phenomena indicated in the causal model.

Similar to the within-category linking technique, the student also creates causal linkages across categories. For example, peer pressure (social phenomenon) and poor body image (psychological phenomenon) may be the cause of poor eating habits and an eating disorder (biological causal mechanisms). The student continues to create various causal linkages within and between categories until he feels the causal model represents an exhaustive illustration of all possible linkages between existing and new concepts. He then evaluates the causal model to ensure that no causal linkages are omitted, that coherent linkages are clearly indicated, and that any conjectural linkages are indicated in a dotted line so they can be explored further.

\section{Phase 3: Identification of Learning Needs.}

Description. Nursing students identify learning needs and engage in self-directed learning by seeking out and appraising resources. 
To complete this phase, nursing students must

1. identify learning gaps related to the relationships in the causal model that are unsupported by evidence and need exploration and justification;

2. search and appraise resources to develop evidence-informed knowledge and refine misconceptions in previous knowledge structures; and

3. apply newly learned ideas to the causal model and critically analyze their relationships.

Application of Phase 3. Building upon the conjectural linkages, the student is able to identify learning gaps that require further justification. For example, the student may propose, through a dotted line, that low self-esteem (psychological phenomenon) causes poor school performance (social phenomenon), which leads to an eating disorder (biological causal mechanism). Since these appear to be sensible and possible relationships, the student may not have sufficient knowledge or evidence to justify his claim. He later identifies resources that will enhance his learning about self-esteem and its effects on school performance and eating disorders. With this specific learning goal, the student is able to identify particular resources to help him answer his specific inquiry, instead of general resources that provide common information about eating disorders.

Through research, the student is able to justify one of his two conceptions. For example, he will learn that poor self-esteem does negatively affect school performance. However, he will also learn that poor self-esteem does not always lead to an eating disorder. In this case, he may realize that he has to reconstruct his misconception about the latter conjectural linkage. Through this self-directed learning, the student is able to critically determine which conjectural linkages are true and which are not. This could allow him to address some of his learning gaps, which may subsequently enhance his understanding of the causal model and the presenting care situation.

In this phase, the student could also decide that it is important for him to learn about new concepts that emerged when developing the causal model. For example, media (a new social causal mechanism) could be explored further in terms of its influence on societal norms, peer pressure, body image, and poor eating habits. Although not apparent in the care situation, phenomena linked to media may be of great importance to the care situation and could create new learning opportunities for the student to help him think outside the box.

\section{Phase 4: Synthesis and Reflection.}

Description. Nursing students integrate their new knowledge and create a coherent conceptualization that explains the salient points of the care situation.

To complete this phase, nursing students must

1. recognize salient points and associations of the care situation in the causal model;

2. synthesize salient points and associations by creating broad-scope conceptualizations (explanatory hypotheses) which best-explain the care situation; and

3. reflect on the conceptualization to ensure it coherently represents prominent relationships between all or the maximum numbers of salient points.

Application of Phase 4. When examining the causal model, the student may realize that some concepts have attracted more linkages than others (e.g., eating disorder, body image, and 
peer pressure). These concepts are the salient points of the care situation. The salient points may emerge either from the detected phenomena, the causal mechanisms, or new concepts added later to the causal model. Once the student recognizes these salient points, he generates a statement or a hypothesis to explain the salient points in a coherent way. Since several phenomena may be recognized as the most salient, students may generate a set of hypotheses to explain the various salient aspects of a care situation and how they may be interrelated. This set of hypotheses is also known as a case formulation (Vertue \& Haig, 2008).

One possible biopsychosocial hypothesis from the example care scenario that the student may create could be, "Teenage girls may develop eating disorders due to the pressure they feel from their peers to live up to socially accepted body images portrayed in the media". The novice nursing student will not retrieve such explanatory hypothesis from a pool of pre-existing hypotheses in the memory. Rather, such a hypothesis is created through developing the causal model which stimulates the mind to discover unique connections which allow certain salient points to emerge. After creating one or a few hypotheses that best explain the care situation, the student reflects on them to ensure they coherently represent the essence of the care situation.

\section{Discussion}

Abductive reasoning and its focus on hypothesis creation offer a new way of examining our previous ideas about the PBL process, which is rooted in hypothetico-deductive reasoning. While hypothetico-deductive reasoning embedded within PBL favours empirical knowing (Monti \& Tingen, 1999), abductive reasoning as a pragmatic approach appears to be more inclusive of multiple modes of knowing. Through abductive reasoning, nursing students could generate plausible hypotheses that aim to explain salient relationships found within a care situation. This can be important in the conceptualization of health situations, which involve various levels of complexity or clients with complex comorbidities.

In relation to scaffolding, which is an act of supporting the learning process (Lajoie, 2005), the proposed abductive reasoning approach to PBL could be introduced as an instructional strategy within the classroom. If facilitated correctly by the educator, the proposed abductive reasoning approach could also promote self-scaffolding, which is viewed as a primary goal of education (Bickhard, 2005). This may occur when students develop causal models and identify and fill knowledge gaps through self-directed learning. Through self-scaffolding, students may be able to use newly acquired knowledge to validate or reconstruct existing knowledge structures in meaningful ways, which could enhance the depth and breadth of their learning. The approach also creates opportunities for the student to self-monitor his learning in each phase (e.g., did I pick up all of the relevant cues before creating a hypothesis?).

Since abductive reasoning may promote the thinking skills required in exploring care situations, it may be a useful approach for educators to use within a PBL context in a classroom setting. The skills that educators may promote with the use of abductive reasoning could potentially contribute to the development of critical and creative thinking, academic achievement, and lifelong learning abilities. This could further provide training for real-life application and decision-making. Moreover, this type of reasoning could be useful in the clinical setting where nursing students are required to deal with real-life care situations and make reallife care-related decisions.

Traditionally, nursing experience has been known to be a prerequisite for the ability to detect salience (Benner, 1984). This view limits novice nursing students' ability to detect salient 
points of a care situation because they lack the exposure to clients in multiple clinical settings, which expert nurses have. However, this paper proposes that novice nursing students could detect salient points of a care situation through the use of abductive reasoning. As a teachinglearning strategy, abductive reasoning could be promoted in the classroom setting by educators who understand abductive reasoning, its philosophy, and its approach to reasoning through care situations. For this to occur, more resources are needed to guide educators on how they can promote abductive reasoning among students.

While students can engage in abductive reasoning independently or as a group for a richer learning experience, the ideas surrounding abductive reasoning and its application to care situations may be abstract for some learners. Without proper training in abductive reasoning, learners may find the proposed abductive reasoning approach to be time-consuming or even difficult to comprehend. While the presented care scenario provides insight on how abductive reasoning principles could be applied to problem-based learning, educators may need to create more case examples to further guide learners on using abductive reasoning to explore care situations.

Although the abductive reasoning process based on the work of Vertue and Haig (2008) has not received any research attention, this paper applies aspects of it to PBL and proposes a new abductive reasoning strategy which could be promoted within undergraduate nursing curricula. However, research is needed to test the proposed abductive reasoning strategy and its influence on hypothesis generation within PBL and non-PBL contexts, as well as the clinical practice setting. Such research will not only contribute to the emerging field of abductive reasoning within nursing education, it may introduce new and improved ways for educators to promote learning and discovery among nursing students and students of other health disciplines.

\section{Conclusion}

The abductive reasoning strategy proposed in this paper provides a pragmatic approach to exploring and explaining a care situation. As a scaffolding technique, the proposed strategy within PBL could enable the broader detection of salient points and the creation of hypotheses, which are important for initiating the process of inquiry among nursing students. The strategy could further help nursing students engage in higher-order thinking, which allows them to evaluate ideas before synthesizing them. It could also enable nursing students to build their knowledge structures in meaningful ways to enhance the depth and breadth of their learning. Since literature on abductive reasoning within nursing is limited, nurse researchers are encouraged to examine the practicality of the proposed abductive reasoning strategy and its influence on nursing students' abilities in phenomena detection and hypothesis creation within PBL or even non-PBL contexts. 


\section{References}

Barrows, H. S. \& Tamblyn, R. M. (1980). Problem-based learning: An approach to medical education. New York, NY: Springer Publishing Company.

Benner, P. (1984). From novice to expert: Excellence and power in clinical nursing practice. Menlo Park, CA: Addison-Wesley.

Bickhard, M. H. (2005). Functional scaffolding and self-scaffolding. New Ideas in Psychology, 23, 166-173. https://doi.org/10.1016/j.newideapsych.2006.04.001

Buckingham, C. D., \& Adams, A. (2000). Classifying clinical decision making: A unifying approach. Journal of Advanced Nursing, 32(4), 981-989. https://doi.org/10.1046/j.13652648.2000.t01-1-01565.x

Chinn, P. L., \& Kramer, M. K. (2014). Knowledge development in nursing: Theory and process (9th ed.). St. Louis, MO: Mosby, Inc.

Deely, J. (1992). Logic as a liberal art: Student edition. Dubuque, IA: Letterheads to Books.

Elstein, A. S., Shulman, L. S., \& Sprafka, S. A. (1978). Medical problem solving: An analysis of clinical reasoning. Cambridge, MA: Harvard University Press.

Eriksson, K., \& Lindström, U. A. (1997). Abduction - A way to deeper understanding of the world of caring. Scandinavian Journal of Caring Sciences, 11(4), 195-198. https://doi.org/10.1111/j.1471-6712.1997.tb00455.x

Fann, K. T. (1970). Peirce's theory of abduction. The Hague, The Netherlands: Martinus Nijhoff.

Fisher, S. D., Gettys, C. F., Manning, C., Mehle, T., \& Baca, S. (1983). Consistency checking in hypothesis generation. Organizational Behavior and Human Performance, 31(2), 233254. https://doi.org/10.1016/0030-5073(83)90123-x

Haig, B. D. (1999). Construct validation and clinical assessment. Behaviour Change, 16(1), 6473. https://doi.org/10.1375/bech.16.1.64

Haig, B. D. (2008). Scientific method, abduction and clinical reasoning. Journal of Clinical Psychology, 64(9), 1013-1018. https://doi.org/10.1002/jclp.20505

Haig, B. D. (2014). Investigating the psychological world: Scientific method in the behavioral sciences. London, UK: The MIT Press.

Ingram, C., Ray, K., Landeen, J., \& Keane, D. R. (1998). Evaluation of an educational game for health sciences students. Journal of Nursing Education, 37(6), 240-246.

Kwon, Y. J., Jeong, J. S., \& Park, Y. B. (2006). Roles of abductive reasoning and prior belief in children's generation of hypotheses about pendulum motion. Science \& Education, 15, 643-656. https://doi.org/10.1007/s11191-004-6407-x

Kwon, Y. J., Lee, J. K., Shin, D. H., \& Jeong, J. S. (2009). Changes in brain activation induced by the training of hypothesis generation skills: An fMRI study. Brain and Cognition, 69(2), 391-397. https://doi.org/10.1016/j.bandc.2008.08.032

Lajoie, S. (2005). Extending the scaffolding metaphor. Instructional Science, 33, 541-557. https://doi.org/10.1007/s11251-005-1279-2 
Lawson, A. E. (1995). Science teaching and development of thinking. Belmont, CA: Wadsworth Publishing Company.

Lawson, A. E., \& Daniel, E. S. (2011). Inferences of clinical diagnostic reasoning and diagnostic error. Journal of Biomedical Informatics, 44(3), 402-412. https://doi.org/10.1016/j.jbi.2010.01.003

Lipscomb, M. (2012). Abductive reasoning and qualitative research. Nursing Philosophy, 13, 244-256. https://doi.org/10.1111/j.1466-769x.2011.00532.x

Longley, P. (1981). Contemporary logic. Washington, DC: University Press of America.

Mirza, N., Akhtar-Danesh, N., Noesgaard, C., Martin, L., \& Staples, E. (2014). A concept analysis of abductive reasoning. Journal of Advanced Nursing, 70(9), 1980-1994. https://doi.org/10.1111/jan.12379

Monti, E. J., \& Tingen, M. S. (1999). Multiple paradigms of nursing science. Advances in Nursing Science, 21(4), 64-80. https://doi.org/10.1097/00012272-199906000-00010

Norman, G. R., Brooks, L. R., Colle, C. L., \& Hatala, R. M. (1999). The benefit of diagnostic hypotheses in clinical reasoning: Experimental study of an instructional intervention for forward and backward reasoning. Cognition and Instruction, 17(4), 433-448. https://doi.org/10.1207/s1532690xci1704_3

Patel, V. L., Arocha, J. F., \& Zhang, J. (2005). Thinking and reasoning in medicine. In K. J. Holyoak \& R. G. Morrison, The Cambridge handbook of thinking and reasoning (pp. 727-750). New York, NY: Cambridge University Press.

Peirce, C. S. (1998). Pragmatism as the logic of abduction. In the Peirce Edition Project (Ed.), The essential Peirce: Selected philosophical writings: Volume 2 (1893-1913) (pp. 226241). Bloomington, IN: Indiana University Press. (Original work published in 1903)

Popper, K. (2013). The open society and its enemies. Princeton, NJ: Princeton University Press. (Original work published in 1945)

Raholm, M. B. (2010a). Abductive reasoning and the formation of scientific knowledge within nursing research. Nursing Philosophy, 11, 260-270. https://doi.org/10.1111/j.1466769x.2010.00457.x

Raholm, M. B. (2010b). Theory development and the logic of discovery. International Journal of Human Caring, 14(3), 36-42.

Reed, G. P. (1995). A treatise on nursing knowledge development for the 21st century: Beyond postmodernism. Advances in Nursing Science, 17(3), 70-84. https://doi.org/10.1097/00012272-199503000-00008

Rideout, E. (2001). Transforming nursing education through problem-based learning. Sudbury, MA: Jones and Bartlett Publishers.

Rideout, E., \& Carpio, B. (2001). The problem-based learning model of nursing education. In E. Rideout (Ed.), Transforming nursing education through problem-based learning (pp. 2149). Sudbury, MA: Jones and Bartlett Publishers. 
Rolfe, G. (1997). Science, abduction and the fuzzy nurse: An exploration of expertise. Journal of Advanced Nursing, 25(5), 1070-1075. https://doi.org/10.1046/j.13652648.1997.19970251070.x

Shank, G. (1998). The extraordinary ordinary powers of abductive reasoning. Theory \& Psychology, 8(6), 841-860. https://doi.org/10.1177/0959354398086007

Simmons, B., Lanuza, D., Fonteyn, M., Hicks, F., \& Holm, K. (2003). Clinical reasoning in experienced nurses. Western Journal of Nursing Research, 25(6), 701-719. https://doi.org/10.1177/0193945903253092

Sumathi, S., \& Saravanavel, P. (2008). Marketing research \& consumer behaviour. New Delhi, India: Vikas Publishing House.

Tanner, C. A., Padrick, K. P., Westfall, U. E., \& Putzier, D. J. (1987). Diagnostic reasoning strategies of nurses and nursing students. Nursing research, 36(6), 358-365. https://doi.org/10.1097/00006199-198711000-00010

Tarski, A. (1941). Introduction to logic and to the methodology of deductive sciences. New York, NY: Oxford University Press.

Thagard, P. (1978). The best explanation: Criteria for theory choice. Journal of Philosophy, 75(2), 76-92. https://doi.org/10.2307/2025686

Vertue, F. M., \& Haig, B. D. (2008). An abductive perspective on clinical reasoning and case formulation. Journal of Clinical Psychology, 49(9), 1046-1068. https://doi.org/10.1002/jclp.20504

Ward, T., \& Haig, B. (1997). Abductive reasoning and clinical assessment. Australian Psychologist, 32(2), 93-100. https://doi.org/10.1080/00050069708257360

Wong, T. K. S. \& Chung, J. W. Y. (2002). Diagnostic reasoning processes using patient simulation in different learning environments. Journal of Clinical Nursing, 11, 65-72. https://doi.org/10.1046/j.1365-2702.2002.00580.x 